\title{
Status of Serum Magnesium level in Diabetic Retinopathy $\&$ Non Retinopathy in the Patients of Type-II Diabetes Mellitus
}

\author{
Ali Raza Memon, Rubina Ahmadani, Jawaid Hussain Laghari, Muhammad Yousuf Memon, \\ Sofia Chandio
}

ABSTRACT

OBJECTIVE: To compare the serum magnesium levels in normal population, non-complicated patients of type - II diabetes mellitus and complicated patients of type- II diabetes mellitus with retinopathy \& to observe the role of serum magnesium in development of retinopathy in patients of type- II diabetes mellitus.

METHODOLOGY: Total 100 subjects were recruited divided in to three groups, group A contain 30 normal subjects consider as control group, group B contain 35 diagnosed cases of type- II diabetes mellitus without retinopathy and group $C$ contain 35 diagnosed cases of type -ll diabetes mellitus with retinopathy. Random blood glucose level was measured by glucose oxidase method; serum magnesium level was measured on Zeeman spectrophotometer. All data was analyzed on SPSS 16 by applying independent student $t$-test.

RESULTS: The Mean Random Blood Glucose level was significantly high $(p<0.05)$ in diabetic patients with retinopathy as compared to with control and diabetic with non-retinopathy groups. The serum magnesium level was significantly $(p<0.001)$ decline in patients of type - II diabetes mellitus with retinopathy as compared with control group and diabetes mellitus without retinopathy.

CONCLUSION: The hypomagnesaemia is one of the provoking factor for the development of diabetic retinopathy along with poor glycemic control and long duration of type - II diabetes mellitus.

KEY WORDS: Type - II Diabetes mellitus, Diabetic Retinopathy, Magnesium.

This article may be cited as: Memon AR, Ahmadani R, Laghari JH, Memon MY, Chandio S. Status of Serum Magnesium level in Diabetic Retinopathy \& Non Retinopathy in the Patients of Type-II Diabetes Mellitus. J Liaquat Uni Med Health Sci. 2018;17(04):221-4. doi: $10.22442 /$ jumhs.181740581

\section{INTRODUCTION}

Diabetic retinopathy is one of the major cause of blindness in diabetic population all over the world ${ }^{1}$. Type - II diabetic patients suffering from diabetes mellitus from last 10 years are more prone to retinopathy ${ }^{2}$. Globally $15-17 \%$ diabetic population suffered from diabetic retinopathy ${ }^{3}$. $10 \%-13 \%$ of Pakistani diabetic population are suffering from diabetic retinopathy, ${ }^{4}$ means these peoples are prone to blindness if not treated properly. Magnesium is the intracellular cation which acts as co-factor in different metabolic pathway of glucose metabolism ${ }^{5}$. Magnesium also acts as insulin sensitizer ${ }^{6}$. In diabetic patients' magnesium may be loss from body due to renal osmosis and glycosuria due to defect in reabsorption of magnesium from renal tubules ${ }^{7}$, so magnesium level decreases in diabetic patients ${ }^{8}$. If magnesium level is not maintaining properly by diet and multivitamins preparations it provokes the complications of diabetes especially retinopathy and nephropathy ${ }^{9}$, therefore the aim of our study to compare the serum magnesium level in non-complicated diabetic type-II population and complicated diabetic type-II population and to evaluate the role of hypomagnesaemia in development of diabetic retinopathy.

\section{METHODOLOGY}

This case control comparative study was carried out at the department of Biochemistry, LUMHS Jamshoro, with the collaboration of diabetic clinic of LUMHS \& Ophthalmology Department Eye Hospital Hyderabad Sindh from October 2011-March 2012. The samples were selected on the basis of non-probability sampling technique. Total 100 samples were selected and divided into three groups, 30 normal people with same age having no diabetes and any other ocular complain known as control group i.e Group A $=35$ diagnosed diabetic type - II patients who have type- II diabetes mellitus from at least last 5-10 years, without any ocular complain included in group B and 35 diagnosed type - II diabetic patients with retinopathy included in group C.

The inclusion criteria were diagnosed cases of Type-II diabetes mellitus patients with or without retinopathy, 
both males \& females between the age of $50-60$ years were included in this study.

Exclusion Criteria: The patients who suffered from dyslipidemia, malnutrition, alcoholism, acute pancreatitis, myocardial infarction, chronic diarrhea were excluded from this study.

The $3 \mathrm{ml}$ of blood was taken from cuboidal venipuncture under aseptic measurement from each subject after centrifugation of blood sample blood glucose level measured by glucose oxidase method and serum Magnesium levels estimated by Polarized Zeeman 2000 Atomic Absorption Spectrophotometer. Examination of retina was performed by indirect ophthalmoscope at eye hospital LUH Hyderabad.

All data was statistically analyzed by SPSS version 16 by applications of independent student't' test.

\section{RESULTS}

The present study was conducted include 100 subjects divided into three groups; group $A$ as control group and group B \& C case study groups. Random blood glucose levels, serum magnesium levels were measured of each participants and indirect ophthalmoscopy of each subject also done to check out the signs of retinopathy.

The mean Random blood glucose levels of control group (group A) was $137 \pm 4.2 \mathrm{mg} / \mathrm{dl}$, group B was $213 \pm 3.8 \mathrm{mg} / \mathrm{dl}$ and group $C$ was $251 \pm 3.1 \mathrm{mg} / \mathrm{dl}$.

The mean serum magnesium levels of group $A$ was $2.1 \pm 0.7 \mathrm{mg} / \mathrm{dl}$, group $B$ was $1.4 \pm 0.4 \mathrm{mg} / \mathrm{dl}$, group $C$ was $1.1 \pm 0.5 \mathrm{mg} / \mathrm{dl}$.

Most of the patients of group $\mathrm{C}$ having non-proliferative diabetic retinopathy.

These results shown that serum magnesium level was statistically decline $(p<0.05)$ in diabetic patients as compared to control group, serum magnesium level was statistically decline (0.001) in diabetic complicated group i.e group $\mathrm{C}$ with compared to group A \& B. It indicates hypomagnesaemia is one of the provoking factors of retinopathy in diabetic populations.

\section{TABLE I: RBS \& SERUM MAGNESIUM LEVELS IN} ALL GROUPS

\begin{tabular}{|c|c|c|l|}
\hline Group & $\begin{array}{c}\text { RBS } \\
(\mathbf{m g} / \mathbf{d l})\end{array}$ & $\begin{array}{c}\text { Serum Magne- } \\
\text { sium }(\mathbf{m g} / \mathbf{d l})\end{array}$ & $\begin{array}{c}\text { Ophthalmoscopy } \\
\text { findings }\end{array}$ \\
\hline A & $137 \pm 4.2$ & $2.1 \pm 0.7$ & No sign Retinopathy \\
\hline B & $213 \pm 3.8$ & $1.4 \pm 0.4^{*}$ & No sign Retinopathy \\
\hline C & $251 \pm 3.1$ & $1.1 \pm 0.5^{* *}$ & $\begin{array}{l}\text { Non-Proliferative } \\
\text { Retinopathy }\end{array}$ \\
\hline
\end{tabular}

(RBS $=$ Random Blood Sugar, $p<0.05, p<0.001)$
GRAPH I: RANDOM BLOOD SUGAR LEVEL

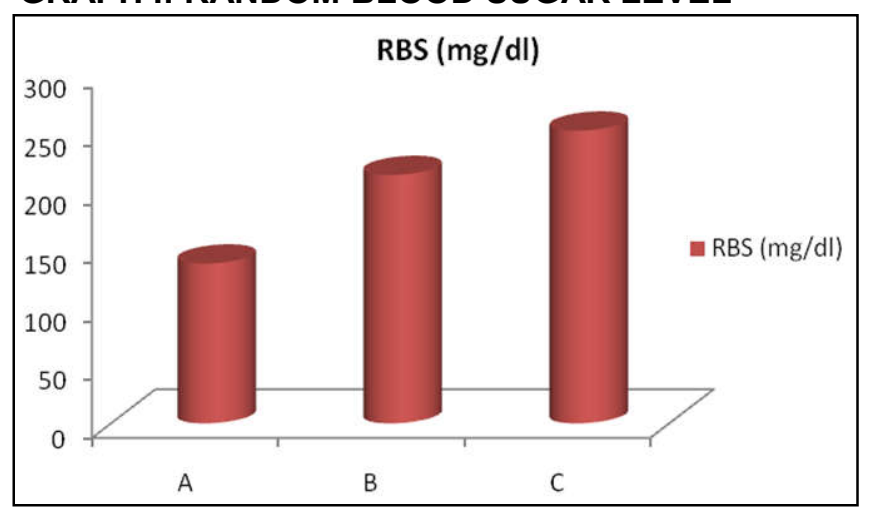

GRAPH II: SERUM MAGNESIUM LEVELS

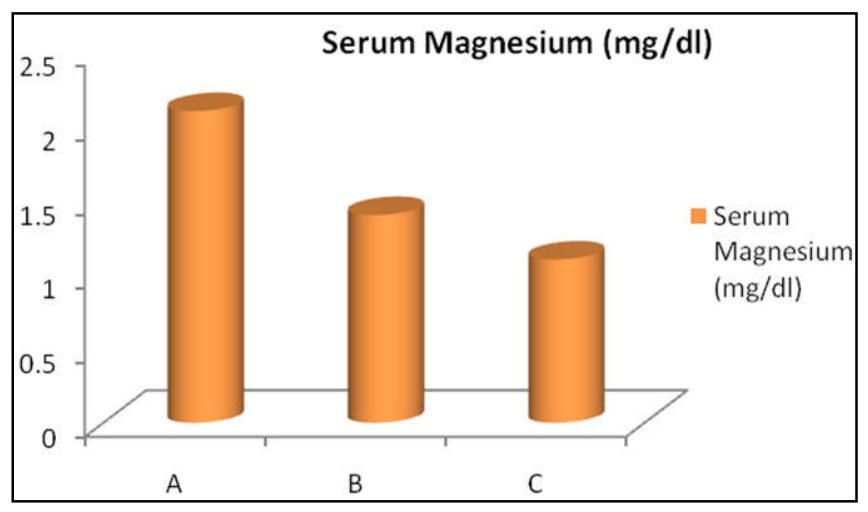

\section{DISCUSSION}

Diabetic retinopathy is a serious problem all over the world. Untreated or improper treatment of diabetes is one of the causes of blindness in diabetic population ${ }^{10}$. The lack of awareness, no proper checkup on the time, diet do not contain proper nutritional values of minerals \& vitamins, medicine not taken properly with proper dose and time and socioeconomic issues, all are contributing factors in development of diabetic complications ${ }^{11}$. The longer duration of diabetes; patients are more prone to develop diabetic complications like retinopathy, nephropathy and neuropathy ${ }^{2}$. Now a days researchers working on the role of minerals and vitamins in diabetic patients to control the diabetic complications $^{12}$. Magnesium also act as co-factor in carbohydrate metabolism as well and also regulate the glucose uptake by glucose transporter GLUT-4 from adipose tissue and maintain the insulin sensitivity $^{13}$. In type-II diabetes mellitus reduced level of serum magnesium can cause the vascular injuries occurs in eye due to increased intracellular formation of advanced glycation end products, activation of protein kinase $C$ isoforms, stimulation of hexosamine 
pathway ${ }^{14}$.

Our study correlates with the study of Siddiqui A $2017^{15}$ observed that serum magnesium level become reduced in diabetic patient and may lead to diabetic vascular complications.

Wahid A $2017^{16}$ concluded that $34 \%$ of type II Diabetic population suffering from decreased level of magnesium and poor glycemic control along with hypomagnesaemia leading to retinopathy.

Phadenis P $2017^{17}$ concluded that development of diabetic retinopathy associated with hypomagnesaemia, hyperlipidemia and microalbuminurea.

All studies along with our study concluded that long duration of type II diabetes mellitus along with hypomagnesaemia are the contributing factors in development of retinopathy.

\section{CONCLUSION}

This study concluded that uncontrolled diabetes is one of the contributing factors in development of diabetic retinopathy and hypomagnesaemia is also provoking factor in development of diabetic retinopathy.

Conflict of Interest: There is no conflict of interest

Funding: This research project is self funded.

\section{REFERENCES}

1. Bourne RR, Jonas JB, Bron AM, Cicinelli MV, Das A, Flaxman SR, et al. Prevalence and causes of vision loss in high-income countries and in Eastern and Central Europe in 2015: magnitude, temporal trends and projections. $\mathrm{Br} \mathrm{J}$ Ophthalmol 2018; 102(05):575-85. Doi: 10.1136/bjophthalmol2017-311258

2. Pande SS, Chutani A. Comparative study of pulmonary function tests with microvascular complications, retinopathy and nephropathy in type 2 Diabetes Mellitus \& correlation with duration of diabetes. Int J Clin Biomed Res 2018; $4(1): 14-22$.

3. Solomon SD, Chew E, Duh EJ, Sobrin L, Sun JK, VanderBeek BL, et al. Diabetic retinopathy: a position statement by the American Diabetes Association. Diabetes Care 2017; 40(3):412-8. doi: 10.2337/dc16-2641.

4. Kazi AA, Laghari NA, Jatoi SM. Current Trends in Diabetic Retinopathy. JLUMHS 2005; 4(1):1-2.

5. Guo W, Nazim H, Liang Z, Yang D. Magnesium deficiency in plants: an urgent problem. The Crop Journal 2016; 4(2):83-91.
6. Bertinato J, Wang KC, Hayward S. Serum magnesium concentrations in the Canadian population and associations with diabetes, glycemic regulation, and insulin resistance. Nutrients 2017; 9(3): pii: E296.

7. Palmer BF, Clegg DJ. Electrolyte and acid-base disturbances in patients with diabetes mellitus. $\mathrm{N}$ Engl J Med 2015; 373(6):548-59. doi: 10.1056/ NEJMra1503102.

8. Gommers LM, Hoenderop JG, Bindels RJ, de Baaij JH. Hypomagnesaemia in type 2 diabetes: A Vicious Circle. Diabetes 2016; 65(1):3-13. doi: $10.2337 / \mathrm{db} 15-1028$.

9. Yossef HM, Ghanem NS, Al-Jarhi UM, Shaker OG. Relation of serum magnesium level to microvascular complications and the components of metabolic syndrome in patients with type 2 diabetes mellitus. Egypt J Intern Med 2017; 29 (3):100-104.

10. Alzahrani SH, Bakarman MA, Alqahtani SM, Alqahtani MS, Butt NS, Salawati EM, et al. Awareness of diabetic retinopathy among people with diabetes in Jeddah, Saudi Arabia. Ther Adv Endocrinol Metab. 2018; 9(4):103-12. doi: $10.1177 / 2042018818758621$.

11. Zheng Y, Ley SH, Hu FB. Global etiology and epidemiology of type 2 Diabetes Mellitus and its complications. Nat Rev Endocrinol 2018; 14(2):89 -98. doi: 10.1038/nrendo.2017.151.

12. Dow $C$, Mancini $F$, Rajaobelina K, Boutron-Ruault MC, Balkau B, Bonnet F, et al. Diet and risk of diabetic retinopathy: A systematic review". Eur J Epidemiol 2018; 33(2):141-156.

13. Morakinyo AO, Samuel TA, Adekunbi DA. Magnesium upregulates insulin receptor and glucose transporter-4 in streptozotocinnicotinamide-induced type-2 diabetic rats. Endocr Regul 2018; 52(1):6-16.

14. Balasuramanyam $M$, Rema $M$, Mohan $V$, Premanand C. Biochemical and molecular mechanisms of diabetic retinopathy". Current Sci 2002; 83(12): 1506-14.

15. Siddiqui A, Ghritlahare R, Kumar B. A Study of Serum lonized Magnesium Levels In Relation To Metabolc Syndrome In Type 2 Diabetic Patients. PARIPEX-Indian J Res 2017; 6(6):5-6.

16. Wahid A, Verma GC, Meena CP, Pathan AR. Study of serum magnesium level in patients with type 2 diabetes mellitus and it's correlation 
with glycosylated hemoglobin and diabetic complications. IJAM 2017; 4(2):311-316.

17. Phadnis $P$, Kamble MA, Daigavane $S$, Tidke P, Gautam S. Prevalence and risk
factors-Hemoglobin A1c, serum magnesium, lipids, and microalbuminuria for diabetic retinopathy: A rural Hospital-based study. J Datta Meghe Inst Med Sci Uni 2017; 12(2):121-132.

AUTHOR AFFILIATION:

Dr. Ali Raza Memon (Corresponding Author) Assistant Professor, Department of Biochemistry Liaquat University of Medical \& Health Scinces (LUMHS), Jamshoro, Sindh-Pakistan.

Email: ali.bio.lumhs@gmail.com, raza.memon@lumhs.edu.pk

Dr. Rubina Ahmadani

Assistant Professor, Department of Physiology

LUMHS, Jamshoro, Sindh-Pakistan.

Dr. Jawaid Hussain Lighari

Assistant Professor, Department of Community Medicine

PUMHS, Shaheed Benazeerabad (Nawabshah).

Dr. Muhammad Yousuf Memon

Professor, Department of Biochemistry

PUMHS Shaheed Benazirabad (Nawabshah).

Dr. Sofia Chandio

M.Phil Student, Department of Biochemistry

LUMHS, Jamshoro, Sindh-Pakistan. 